\title{
Florent Montaclair, Le Vampire dans la littérature romantique française 1820-1868
}

\section{Valentina Ponzetto}

\section{(2) OpenEdition}

1 Journals

\section{Edizione digitale}

URL: https://journals.openedition.org/studifrancesi/3118

DOI: $10.4000 /$ studifrancesi.3118

ISSN: 2421-5856

\section{Editore}

Rosenberg \& Sellier

\section{Edizione cartacea}

Data di pubblicazione: 1 juillet 2013

Paginazione: 463

ISSN: 0039-2944

\section{Notizia bibliografica digitale}

Valentina Ponzetto, «Florent Montaclair, Le Vampire dans la littérature romantique française 1820-1868»,

Studi Francesi [Online], 170 (LVII | II) | 2013, online dal 30 novembre 2015, consultato il 02 février 2023. URL: http://journals.openedition.org/studifrancesi/3118; DOI: https://doi.org/10.4000/studifrancesi. 3118

Questo documento è stato generato automaticamente il 2 février 2023.

\section{(c) 9 (1) $\Theta$}

Creative Commons - Attribuzione - Non commerciale - Non opere derivate 4.0 Internazionale - CC BYNC-ND 4.0

https://creativecommons.org/licenses/by-nc-nd/4.0/ 


\title{
Florent Montaclair, Le Vampire dans la littérature romantique française
} 1820-1868

\author{
Valentina Ponzetto
}

\section{NOTIZIA}

FLORENT MONTACLAIR, Le Vampire dans la littérature romantique française 1820-1868, Besançon, Presses universitaires de Franche-Comté, 2010, pp. 444.

1 Caratterizzato da un certo tono didattico per non dire scolastico, il presente volume si compone di due parti, un saggio critico introduttivo, di impostazione storico-letteraria, e un'antologia. A dire il vero si può dire che tutto il libro sia una sorta di antologia critica commentata, perché anche nella sezione saggistica alcuni capitoli sono seguiti da un'appendice antologica, rispettivamente una delle Lettres juives di Boyer d'Argens, primo testo letterario dedicato ai vampiri, una scelta di testi sulle streghe, e una di «extraits qui illustrent la présence du surnaturel dans la littérature avant la période romantique», dalle Mille e una notte a Mérimée.

2 L'antologia vera e propria (pp. 191-438), a sua volta bipartita, comprende dapprima una sezione di «annessi» di carattere manualistico, ovvero una «Bibliographie sommaire» (pp. 201-206), repertorio scelto con criteri non specificati di una ventina di racconti e un buon numero di film di tema vampirico, più un breve riassunto delle definizioni di «fantastico» proposte da altrettanti grandi critici: Roger Caillois nell'introduzione alla sua Anthologie du fantastique (1965), Witold Ostrowski in The Fantastic and the Realistic in literature (1966), e Tzsvétan Todorov in Introduction à la littérature fantastique (1971). Segue una scelta di sei testi narrativi e teatrali fondamentali per tratteggiare la figura del vampiro romantico in terra di Francia, presentati in versione integrale: la novella seminale Le Vampire di Polidori (1819), ritratto del primo vampiro letterario bello, affascinante, aristocratico, furiosamente byroniano e scandalosamente impunito, testo 
a lungo attribuito al medesimo Byron e qui presentato nella traduzione francese del 1864; il romanzo di Cyprien Bérard Lord Ruthwen ou les vampires (1820), prima incarnazione francese del vampiro romantico; il melodramma Le Vampire di Charles Nodier su musica di Piccini (1820), il «drame fantastique» omonimo di Alexandre Dumas et Auguste Macquet (1851) e l'irriverente vaudeville Les Vampires di Scribe (1820), tutti e tre direttamente e immediatamente ispirati alle due opere precedenti; e infine la più originale e melanconica novella La Morte amoureuse di Théophile Gautier. Un poco surrettiziamente si aggiungono in coda all'antologia, quasi in guisa di settimo testo, brani scelti del Lokis di Mérimée, novella che a dire il vero non tratta di vampiri ma di un inquietante conte lituano che si scopre a poco a poco essere il frutto dello stupro di una donna da parte di un orso.

3 Il saggio segue l'evoluzione del vampiro da mito folklorico dell'Europa orientale a motivo letterario occidentale, e in particolare a figura ricorrente dell'immaginario romantico. Una prima parte storico-filologica passa in rassegna le prime definizioni sette-otocentesche del termine "vampiro» e il substrato culturale che ha visto lo svilupparsi del mito nel corso del xvil secolo. Opponendosi alle versioni «universalizzanti» di tale mito, l'A. lo vede come una credenza legata a precise ragioni storico-culturali: per gli Ungheresi e i Bulgari, il vampiro sarebbe un simbolo dell'oppressione turca, «manifestation de l'agression d'un peuple oriental sur un autre peuple oriental qui a changé de civilisation pour prendre les caractères chrétiens et slaves» (p. 28). Attraverso un percorso non sempre limpido, fra ellissi e digressioni, come quella, assai lunga, sulle streghe, l'A. segue poi le metamorfosi che portano il vampiro a diventare dapprima «un simple motif intellectuel, une figure de fantaisie», quindi un personaggio letterario di successo intorno al 1820. Un'ultima parte, forse la più coerente e convincente, analizza le specificità e le manifestazioni del vampiro «romantico», alla Lord Ruthwen, nobile, misterioso, possente, affascinante, a tratti anche tormentato e segnato da profonde contraddizioni. Una tipologia di personaggio che conoscerà ancora incarnazioni gloriose con il Dracula di Bram Stoker a fine Ottocento e con il ciclo romanzesco di Anne Rice negli anni '70.

4 Gli appassionati di letteratura fantastica e vampirica in particolare troveranno in questo volume spunti interessanti, e soprattutto una buona scelta di testi. Il saggio pecca tuttavia per indecisione e rapsodismo: da un lato il pubblico target non è sempre chiaro, dato che la scrittura oscilla fra il saggio accademico e la "guida alla lettura» scolastica, dall'altro volendo toccare troppi aspetti del tema senza mai approfondirli né a volte mostrare chiaramente le loro connessioni, il testo finisce col perdere di precisione, coerenza e ... mordente. Senza contare che si resta quanto meno perplessi di fronte ad una concezione estremamente elastica del romanticismo, che sembra rappresentare per l'autore, più che un movimento letterario, una categoria dello spirito o una tipologia di eroe «révolté, décalé, exclu et combatif [...] en rupture avec son milieu» (p. 181), visto che, dichiaratamente, «cet essai se maintient [...] dans le champ des trois grandes périodes romantiques de la littérature occidentale (1820-1850; 1895-1910; 1975-2001)» (p. 4). Altrettanta o maggiore perplessità susciterà poi la «Conclusione», in cui psicanalisi, medicina e occultismo (sic!) sono messe sullo stesso piano e rapidamente congedate come discipline che, pur avendo trattato la figura del vampiro, non sono in grado di coglierne l'aspetto letterario, ludico e immaginario. 